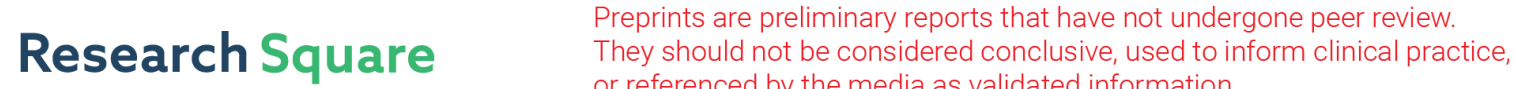 or referenced by the media as validated information. \\ The impact of equity factors on receipt of timely appropriate care for children with suspected malaria in eastern Uganda
}

\section{David Humphreys}

Karolinska Institutet

Joan Nakayaga Kalyango ( $\square$ nakayaga2001@yahoo.com )

Makerere University Uganda

\section{Tobias Alfven}

Karolinska Institutet

\section{Research}

Keywords: Equity, Uganda, care-seeking, malaria, fever, child mortality

Posted Date: April 27th, 2020

DOI: https://doi.org/10.21203/rs.3.rs-23248/v1

License: (1) This work is licensed under a Creative Commons Attribution 4.0 International License.

Read Full License

Version of Record: A version of this preprint was published at BMC Public Health on October 16th, 2021. See the published version at https://doi.org/10.1186/s12889-021-11908-0. 


\section{Abstract}

\section{Introduction}

Malaria accounts for more than one-tenth of sub-Saharan Africa's 2.8 million annual childhood deaths, and remains a leading cause of post-neonatal child mortality in Uganda. Despite increased communitybased treatment in Uganda, children continue to die because services fail to reach those most at risk. This study explores the influence of two key equity factors, socioeconomic position and rurality, on whether children with fever in eastern Uganda receive timely access to appropriate treatment for suspected malaria.

\section{Methods}

Data were collected from 1,094 caregivers of children aged 6-59 months on: illness and care-seeking during the previous two weeks, treatment received, and treatment dosing schedule. Additional data on rurality and household socioeconomic position were extracted from the Iganga-Mayuge Health and Demographic Surveillance Site (HDSS) database. A child was considered to have received prompt and appropriate care for symptoms of malaria if they received the recommended drug in the recommended dosing schedule on the day of symptom onset or the next day. Unadjusted and adjusted logistic regression models were developed to explore associations of the two equity factors with the outcome.

\section{Results}

Seventy-four percent of children had symptoms of illness in the preceding two weeks, of which fever was the most common. Children from rural households were statistically more likely to receive prompt and appropriate treatment with artemisinin-combination therapy than their semi-urban counterparts (OR 2.32, $\mathrm{Cl}$ 1.17-4.59, $\mathrm{p}=0.016)$. This association remained significant following application of an adjusted regression model that included the age of the child, caregiver relationship, and household wealth index (OR 2.4, $p=0.036)$. Wealth index in its own right did not exert a significant effect for children with reported fever (OR for wealthiest quintile $=1.02, \mathrm{Cl} 0.48-2.15, \mathrm{p}=0.958$ ).

\section{Conclusions}

The findings from this study help to identify the role and importance of two key equity determinants on care seeking and treatment receipt for fever in children. Whilst results should be interpreted within the limitations of data and context, further studies have the potential to assist policy makers to target inequitable social and spatial variations in health outcomes as a key strategy in ending preventable child morbidity and mortality.

\section{Introduction}

Despite significant reductions in global child mortality achieved during the past quarter of a century, almost five and a half million children under the age of five continue to die around the world every year, 
largely from preventable causes. $(1,2)$ If present trends continue, modelling suggests 3.8 million children will still die unnecessarily in the year 2030.(3) Over half of these deaths occur in sub-Saharan Africa, where mortality rates some fourteen times greater than that of high income regions are driven by low intervention coverage due to weak delivery systems, poor linkages with maternal health programmes, and gaps in the continuum of care, among other factors. $(2,4,5)$

In Uganda, leading causes of childhood mortality closely mirror those of sub-Saharan Africa as a whole. Despite concerted control efforts as part of the Ministry of Health's strategic plan, malaria continues to account for over one tenth of all childhood deaths.(6) Timely access to good health care is crucial to enable prompt diagnosis and the commencement of effective antimalarial treatment. However, despite upscaling access to rapid diagnostic tests (RDTs) and artemesinin-based combination therapies (ACTs) children continue to die from malaria in settings where services are fragmented and fail to reach those most at risk.(7)

Building upon the Integrated Management of Childhood Illness (IMCI) strategy which started in Uganda in 1996, a policy promoting community-based testing and treatment of malaria initially through the homebased management of fever was established in 2002. The aim of this strategy was to improve access to health care for the rural poor who traditionally have lacked financial resources for transportation to distant health facilities.(8) In 2010, this strategy was expanded to include management of pneumonia and diarrhoea under the integrated community case management strategy (iCCM). The principles of iCCM have scaled up community-level care delivery where it is most needed, particularly in rural areas.

However, even when basic primary health care is available, care-seeking is influenced by multiple other factors including (but not limited to): recognition of a child's symptoms by the caregiver, perception of symptom severity, and a diverse array of barriers beyond the caregiver's control. These barriers, such as the cost of accessing and purchasing treatment and distance to the nearest point of care, may greatly impact decisions regarding care-seeking and so perpetuate existing inequalities in health outcomes.

The central role equity plays in improving health and development outcomes is emphasised in both the United Nations's 2030 Agenda for Sustainable Development and associated Sustainable Development Goals (SDGs). Goal ten specifically provokes member states to work together to "reduce inequality within and between countries".(9) At a country level, delivery of important health interventions often remains poorest where the needs are greatest.(10) National averages thus oft belie important inequities, with significant disparities characterising those receiving access to local health services.(11) Addressing inequality with regard to child health is an ongoing and increasing focus for research and policy makers alike. (12-14).

Given the need to understand the impact of health determinants upon the goal of achieving more equitable health outcomes, this study aimed to explore the influence of socioeconomic position and rurality on care-seeking for children aged 6-59 months with fever in eastern Uganda. 


\section{Methods}

\section{Study setting}

Survey data used for this analysis were obtained from the Iganga-Mayuge Health and Demographic Surveillance Site (HDSS) in eastern Uganda, a collaboration between the Makerere University School of Public Health and the Karolinska Institutet. The HDSS covers a total area of 3,931 square kilometres and straddles the border between the two districts of Iganga and Mayuge in Uganda's east, approximately 120 kilometres from the capital Kampala. Consisting of 65 villages, the region is predominantly rural with a largely subsistence-agricultural economy. The total population of the area is approximately 79,910 (15), of whom approximately 17 percent are children under the age of five years.(16)

Data were attained using a household questionnaire in a setting where a cluster Randomized-Controlled Trial (cRCT) was ongoing.(17) The purpose of this CRCT study was to compare community-based management of malaria alone to the integrated community-based management of malaria and nonsevere pneumonia.(18-21) Under the CRCT, the HDSS was divided into intervention and control areas. In both areas, Community Health Workers (CHWs) provided care for malaria symptoms among children aged 6-59 months.

\section{Data collection}

The household questionnaire was administered by trained research assistants to 1,095 caregivers of children aged between 6 and 59 months. All participating caregivers gave informed consent prior to inclusion in the study.

Information collected in the questionnaire pertained to whether a child under their care had been unwell in the previous two weeks and, if so, symptomatology, care-seeking behaviour, and any treatment received. Significant efforts were employed during interviews to improve the validity of treatment reporting by caregivers. Examples included the use of medicine posters showing drugs commonly used in the area to assist correct identification of treatment received, and cross-checking with medication packages to confirm the drug and dose prescribed, where these were available.

Data relating to both the location of households (rural versus semi-urban) and their corresponding assetwealth quintiles were extracted from the Iganga-Mayuge HDSS, imported, and merged with the existing questionnaire dataset using unique identifiers. Composite variables were devised to operationalize the outcome of interest, specifically whether the child in question received prompt and appropriate care for fever.

Figure 1 outlines the sampling framework for this study. Initially, 1,400 children aged 6-59 months were sampled from the HDSS database (700 from the intervention and 700 from the control areas). Among these, caregivers of 1,095 children completed the survey questionnaire. One response was excluded as the child in question lay outside the target age range for this sub-study (being 6 months to 5 years). Children who hadn't been unwell in the two weeks prior to interview $(n=284)$, and those with symptoms 
not relating to malaria (i.e. no fever, $n=57$ ), were also excluded. A period of two weeks was considered suitable for analysis since longer periods may have resulted in recall bias which may have impacted the quality of the data associated with care sought and treatment received.

The Iganga-Mayuge HDSS undertakes regular updates of household wealth status based on a modified asset score similar to that employed by the Demographic and Health Surveys (DHS) Program.(22) Additionally, households within the HDSS are classified as either rural or semi-urban, based on population size and proximity to regional centres. Both classifications were maintained and data were matched with the corresponding households of the caregivers participating in the questionnaire survey.

Appropriate treatment of subjective fever, the sole symptom considered for a clinical diagnosis of malaria, was defined as the child receiving an appropriate antimalarial (based on national guidelines), at the right frequency and dose, for the correct duration.(23) Prompt commencement of treatment necessitated drug commencement on the same or next day following the recognition of signs or symptoms in the child. This definition has been applied previously as a temporal measure of 24 hours in a setting and culture where watches are seldom worn. $(24,25)$ A total of 58 cases were excluded from analysis due to missing data which led to a lack of clarity whether prompt, appropriate treatment was received.

\section{Data analysis}

Stata 13 (StataCorp., TX, USA) was employed to perform analyses for this study. Baseline characteristics of the study population were summarized using descriptive statistics, with bivariate analyses being undertaken using Pearson's chi-squared test, Fisher's exact test, and the Kruskal-Wallis rank sum test. Variables that had a p-value of $<0.2$ on bivariate analysis were included in the adjusted logistic regression model. Rate differences and ratios were calculated for analysis of wealth index and rurality against prompt and appropriate access to treatment.

Reference groups were defined to either reflect the most common scenario (for example, the relationship of caregiver to child being mother), or those potentially most disadvantaged (for example, rural location, lowest wealth quintile) in order to observe for protective effect.

\section{Results}

\section{Characteristics of study population}

After excluding those children who didn't have symptoms of illness within the two weeks preceding questionnaire completion, those with symptoms other than fever, and missing information precluding definitive outcome measurement, data from a total of 695 caregivers were included for analysis. The sample characteristics of these caregivers and their children are presented in Table 1. The average age of children was 33.8 months. Mothers were the primary caregiver in three-quarters (75 percent) of cases. Eighty-three percent of questionnaire respondents resided in rural areas. The proportion of the sample 
belonging to various wealth quintiles varied from 22 percent in the middle quintile to 10 percent in the highest quintile. Information pertaining to wealth status was missing for 14 percent of the survey population. 
Table 1

Sample characteristics of study population

\section{Socioeconomic and}

demographic characteristics

Total number of completed questionnaires for children aged 6-59 months with fever during the past 2 weeks

\section{Age of child}

Mean (S.D.), months

6 months -1 year

$1-3$ years

$3-5$ years

Missing

TOTAL

\section{Sex of child}

Female

Male

TOTAL

\section{Caregiver relationship to child}

Mother

Father

Aunt

Uncle

Grandmother

Grandfather

Other*

Missing

TOTAL
Total

n $\%$

695100

$33.8(14.6)$

$\begin{array}{ll}62 & 8.9\end{array}$

$297 \quad 42.7$

$333 \quad 47.9$

$3 \quad 0.4$

695100

$362 \quad 52.1$

$333 \quad 47.9$

695100

Wealth index (quintiles)

Lowest

$115 \quad 16.6$

Other: sister (3), sister-in-law (1), step-mother (4) 


\begin{tabular}{|lll|}
\hline Socioeconomic and & \multicolumn{3}{c|}{ Total } \\
\cline { 2 - 4 } demographic characteristics & $\mathbf{n}$ & $\%$ \\
\hline 2nd & 129 & 18.6 \\
\hline Middle & 150 & 21.6 \\
\hline 4th & 130 & 18.7 \\
\hline Highest & 72 & 10.4 \\
\hline Missing & 99 & 14.2 \\
\hline TOTAL & 695 & 100 \\
\hline Rurality & & \\
\hline Semi-urban & 115 & 16.6 \\
\hline Rural & 580 & 83.4 \\
\hline TOTAL & 695 & 100.00 \\
\hline Other: sister (3), sister-in-law (1), step-mother (4) & & \\
\hline Reporting Of Symptoms by Caregivers & & \\
\hline
\end{tabular}

In the two weeks prior to the questionnaire being completed, almost three quarters (74 percent) of all caregivers surveyed reported their child had symptoms of illness (not limited to malaria). Overwhelmingly, fever was the most common symptom reported (93 percent of those unwell), either in isolation or in conjunction with other symptoms.

Symptom reporting was highest among caregivers from households in the poorest wealth quintile, 80 percent of whom reported their child had been unwell during the preceding two weeks. Proportionately higher rates of illness were reported among children living in rural areas (76 percent) compared to semiurban dwellers (68 percent).

\section{Timely and appropriate care for symptoms of malaria}

Table 2 presents bivariate and multivariable analyses for children with fever. Due to the composite nature of the outcome variable, missing data meant only 695 observations were included in the final statistical analysis. 
Table 2

Bivariate and adjusted analyses for children with symptoms of malaria

\begin{tabular}{|c|c|c|c|c|c|c|c|c|c|c|}
\hline \multirow{3}{*}{$\begin{array}{l}\text { Socio-economic } \\
\text { and } \\
\text { demographic } \\
\text { characteristics }\end{array}$} & \multicolumn{10}{|c|}{ Child received timely and appropriate treatment for symptoms of malaria? } \\
\hline & \multicolumn{2}{|c|}{ Total } & \multicolumn{2}{|c|}{ Yes } & \multicolumn{2}{|c|}{ No } & \multicolumn{2}{|c|}{ Crude } & \multicolumn{2}{|c|}{ Adjusted } \\
\hline & $\mathbf{n}$ & $\%$ & $\mathrm{n}$ & $\%$ & $\mathrm{n}$ & $\%$ & $\begin{array}{l}\text { OR } \\
\text { (95\% } \\
\text { C.I.) }\end{array}$ & $\begin{array}{l}\mathrm{P}- \\
\text { value }\end{array}$ & $\begin{array}{l}\text { OR } \\
\text { (95\% } \\
\text { C.I.) }\end{array}$ & $\begin{array}{l}\mathrm{P} \text { - } \\
\text { value }\end{array}$ \\
\hline $\mathrm{n}$ & 695 & 100.0 & & & & & & & & \\
\hline \multicolumn{11}{|c|}{ Age of child (months) } \\
\hline Mean (95\% C.I.) & \multicolumn{2}{|c|}{$\begin{array}{l}33.80 \\
(32.71- \\
34.88)\end{array}$} & \multicolumn{2}{|c|}{$\begin{array}{l}31.30 \\
(28.51- \\
34.10)\end{array}$} & \multicolumn{2}{|c|}{$\begin{array}{l}34.29 \\
(33.12- \\
35.47)\end{array}$} & & 0.044 & $\begin{array}{l}0.99 \\
(0.97- \\
1.00)\end{array}$ & 0.082 \\
\hline
\end{tabular}

\section{Sex of child}

\begin{tabular}{|c|c|c|c|c|c|c|c|c|}
\hline Female & 362 & 52.1 & 56 & 48.7 & 306 & 52.8 & 1 & Ref \\
\hline Male & 333 & 47.9 & 59 & 51.3 & 274 & 47.2 & $\begin{array}{l}1.18 \\
(0.79- \\
1.76)\end{array}$ & 0.426 \\
\hline
\end{tabular}

$\begin{array}{llll}\text { TOTAL } & 695 & 115 & 580\end{array}$

Caregiver relationship to child

\begin{tabular}{|c|c|c|c|c|c|c|c|c|c|c|}
\hline Mother & 518 & 74.5 & 79 & 68.7 & 439 & 75.7 & 1 & Ref & 1 & Ref \\
\hline Father & 69 & 9.9 & 14 & 12.2 & 55 & 9.5 & $\begin{array}{l}1.41 \\
(0.75- \\
2.67)\end{array}$ & 0.283 & $\begin{array}{l}1.55 \\
(0.79- \\
3.06)\end{array}$ & 0.205 \\
\hline
\end{tabular}

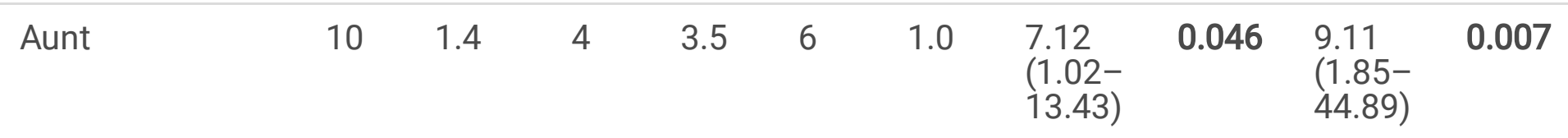

$\begin{array}{|lllllllllll|}\text { Uncle } & 1 & 0.1 & 0 & 0.0 & 1 & 0.2 & & & & \\ \text { Grandfather } & 57 & 8.2 & 12 & 10.4 & 45 & 7.8 & \begin{array}{l}1.48 \\ (0.75-\end{array} & 0.257 & \begin{array}{l}1.39 \\ (0.65-\end{array} & 0.396 \\ & & & & & & & \begin{array}{l}0.93) \\ 2.94)\end{array} & \end{array}$

$\begin{array}{lllllllllll}\text { Grandmother } & 9 & 1.3 & 0 & 0.0 & 9 & 1.6 & & & \\ \text { Other* } & 8 & 1.2 & 1 & 0.9 & 7 & 1.2 & \begin{array}{l}0.79 \\ (0.10-\end{array} & 0.830 & \begin{array}{l}0.97 \\ (0.11-\end{array} & 0.980 \\ & & & & & & & 6.54) & 8.47) & \\ & & & & & & & & \\ & & & & & \end{array}$

$\begin{array}{lllllll}\text { Missing } & 23 & 3.3 & 5 & 4.4 & 18 & 3.1 \\ \text { TOTAL } & 695 & & 115 & & 580 & \end{array}$

*Other: sister (3), sister-in-law (1), step-mother (4) 


\begin{tabular}{|c|c|c|c|c|c|c|c|c|c|c|}
\hline \multirow{3}{*}{$\begin{array}{l}\text { Socio-economic } \\
\text { and } \\
\text { demographic } \\
\text { characteristics }\end{array}$} & \multicolumn{10}{|c|}{ Child received timely and appropriate treatment for symptoms of malaria? } \\
\hline & \multicolumn{2}{|c|}{ Total } & \multicolumn{2}{|l|}{ Yes } & \multicolumn{2}{|l|}{ No } & \multicolumn{2}{|l|}{ Crude } & \multicolumn{2}{|c|}{ Adjusted } \\
\hline & $\mathbf{n}$ & $\%$ & $\mathbf{n}$ & $\%$ & $\mathbf{n}$ & $\%$ & $\begin{array}{l}\text { OR } \\
\text { (95\% } \\
\text { C.I.) }\end{array}$ & $\begin{array}{l}\mathrm{P} \text { - } \\
\text { value }\end{array}$ & $\begin{array}{l}\text { OR } \\
\text { (95\% } \\
\text { C.I.) }\end{array}$ & $\begin{array}{l}\mathrm{P} \text { - } \\
\text { value }\end{array}$ \\
\hline \multicolumn{11}{|c|}{ Wealth index (quintiles) } \\
\hline Lowest & 115 & 16.6 & 22 & 19.1 & 93 & 16.0 & 1 & Ref & 1 & Ref \\
\hline 2nd & 129 & 18.6 & 21 & 18.3 & 108 & 18.6 & $\begin{array}{l}0.82 \\
(0.43- \\
1.59)\end{array}$ & 0.560 & $\begin{array}{l}0.81 \\
(0.41- \\
1.60)\end{array}$ & 0.543 \\
\hline Middle & 150 & 21.6 & 26 & 22.6 & 124 & 21.4 & $\begin{array}{l}0.89 \\
(0.47- \\
1.66)\end{array}$ & 0.707 & $\begin{array}{l}0.86 \\
(0.44- \\
1.67)\end{array}$ & 0.658 \\
\hline 4th & 130 & 18.7 & 15 & 13.0 & 115 & 19.8 & $\begin{array}{l}0.55 \\
(0.27- \\
1.12)\end{array}$ & 0.101 & $\begin{array}{l}0.58 \\
(0.28- \\
1.23)\end{array}$ & 0.156 \\
\hline Highest & 72 & 10.4 & 14 & 12.2 & 58 & 10.0 & $\begin{array}{l}1.02 \\
(0.48- \\
2.15)\end{array}$ & 0.958 & $\begin{array}{l}1.42 \\
(0.64- \\
3.17)\end{array}$ & 0.389 \\
\hline Missing & 99 & 14.2 & 17 & 14.8 & 82 & 14.1 & & & & \\
\hline TOTAL & 695 & & 115 & & 580 & & & & & \\
\hline \multicolumn{11}{|l|}{ Rurality } \\
\hline Semi-urban & 115 & 16.6 & 10 & 8.7 & 105 & 18.1 & 1 & Ref & 1 & Ref \\
\hline Rural & 580 & 83.4 & 105 & 91.3 & 475 & 81.9 & $\begin{array}{l}2.32 \\
(1.17- \\
4.59)\end{array}$ & 0.016 & $\begin{array}{l}2.40 \\
(1.06- \\
5.45)\end{array}$ & 0.036 \\
\hline TOTAL & 695 & & 115 & & 580 & & & & & \\
\hline
\end{tabular}

With mothers being the predominant caregiver surveyed and employed as the reference group, the role of aunty as caregiver demonstrated a protective relationship (OR 7.12, $\mathrm{Cl} 1.02-13.43, \mathrm{p}=0.046)$. This association remained significant following application of an adjusted regression model that also included the age of the child, rurality, and household wealth index (OR 9.11, $\mathrm{Cl} 1.85-44.89, \mathrm{p}=0.007$ ), albeit with a very wide confidence interval.

Wealth index in its own right did not exert a significant effect for children with reported isolated fever (OR for wealthiest quintile $=1.02, \mathrm{Cl} 0.48-2.15, \mathrm{p}=0.958$ ). 
In terms of rurality, data demonstrated an association whereby children from rural households were statistically more likely to receive prompt and appropriate care for fever than their semi-urban counterparts (OR 2.32, $\mathrm{Cl} 1.17-4.59, \mathrm{p}=0.016)$. This association remained significant following application of the adjusted regression model described above (OR 2.4, $p=0.036$ ).

\section{Specific equity range measures}

Calculation of a rate ratio demonstrated no difference among children presenting with fever: that is, those from the highest wealth quintile were no less likely to receive prompt and appropriate care than those in the lowest.

For rurality however, being from a rural household appeared protective: children from semi-urban households were almost half ( 0.45 times) as likely to receive timely appropriate care than their rural counterparts.

\section{Discussion}

\section{Reporting of symptoms}

Nearly three quarters (74 percent) of caregivers reported their child had been unwell during the two weeks prior to being surveyed -69 percent of those surveyed with fever being the chief symptom. This represents a high proportion, but is consistent with previous data from Uganda.(26) The 2016 Ugandan Demographic and Health Survey (DHS) reported 66 percent of children under five in the Busoga region (which includes Iganga and Mayuge districts) had fever during the preceding two weeks; the most recent Malaria Indicator Survey (MIS) estimated a preceding two-week fever prevalence of 47 percent among children from the same region.(27)

The higher rates of symptom-reporting for children from both rural and the poorest households remains consistent with evidence that both demographic cohorts experience a higher burden of disease than that of their urban, wealthier counterparts. $(28,29)$ Enhanced community sensitization, both as a result of being located in an HDSS, and the added data collection associated with the larger on-going CRCT, may also have played a role in increasing awareness of and vigilance in recognising and reporting symptoms.

\section{The relationship of caregivers}

A disproportionate burden of caregiving was placed on female figures within the household, principally mothers, who accounted for almost three-quarters (74.5 percent) of caregivers surveyed. This is consistent with previous country-level gender assessments, which continue to recognise the large proportion of unpaid "care" work in the household, including child and elder care, undertaken by women.

The statistically significant protective role aunts appear to play as primary caregivers was an interesting albeit unanticipated outcome. Whilst not an equity factor per se, the small sample size and wide 
confidence intervals suggest further exploration may be warranted if robust conclusions about the practical significance of this relationship are to be made.

\section{The role of wealth}

Previous studies have demonstrated that those in the poorest wealth quintile experience greatest delays in accessing care.(23) Even in settings where "free" health services exist, poverty is associated with a delay in care-seeking. This study, whilst not demonstrating a significant association, sought to extend such previous studies beyond care-seeking to encompass the goal of receiving timely appropriate treatment.

This lack of an observed effect is likely to be multifactorial. Small sample size, missing data, and inadequate power may have contributed. The additional fact that the broader HDSS, wherein the quintiles are formulated, is a generally homogenous socioeconomic area (that is, the absolute difference in assetwealth from the poorest to the least poor is not that marked) may also play a role in buffering the socioeconomic gradient.

So too, the effect of Community Health Workers (CHWs) which have been employed in the area for some time, may have served to reduce the effect of wealth-related inequality - however further targeted research would be necessary to adequately evaluate this hypothesis.

\section{The role of rurality}

The influence of rural or semi-urban location was significant for children with symptoms of malaria. Children from rural households with fever were more likely to receive prompt and appropriate malaria treatment than their peri-urban counterparts. One possible explanation for this result may relate to the historical tendency for $\mathrm{CHWs}$ - and people living in endemic areas - to associate fever with malaria. As a result, awareness of fever as a symptom is high in rural areas where transmission rates are highest and a historical tendency emphasising presumptive treatment has been challenging to modify at both community and health system levels. $(31,32)$ Better CHW coverage in rural areas likely also played a significant role: whilst urban areas have higher drug shop penetration, some of these may provide inappropriate treatment not aligning with recommended antimalarial therapy.

There may also be a hidden association linking cases of children from wealthier and urban settings. Small numbers in both the highest wealth index group (quintile $5 n=14$ ) and the urban group receiving care $(n=10)$ mean any parallel effect could be due to the same sample group, a recognised limitation to wealth stratification alongside geographical location.(33) As with the findings from wealth stratification, increased sample size and study power would clarify if any underlying association was present.

\section{Methodological considerations}

Important methodological and data limitations impacted upon the analysis and findings of this study. First, a lack of available data concerning other equity and demographic variables including, for example, caregiver education status and birth order, limited the study's scope significantly. Whilst extensive 
evidence has highlighted the importance of rurality and socioeconomic status on both childhood mortality and coverage of health interventions $(26,34)$, consideration of additional equity factors would have facilitated a more comprehensive examination. Second, owing largely to the composite nature of the outcome variables, missing data significantly limited the sample size for analysis. Finally, the collection of data in circumstances where a cRCT was ongoing may have led to increased public awareness, influencing symptom recognition and care seeking behaviour among caregivers at the time of data collection.

Rapid advances in point-of-care malaria diagnostics have also made positive impacts in low-resource settings, including Uganda. Since 2010, the World Health Organization has recommended confirmation of all suspected malaria cases by microscopy or rapid diagnostic tests (RDTs) before treatment (35). Indeed, the IMCl guidelines for high-risk malaria settings promote testing wherever available (36). Thus, with time and increased resourcing, widespread empiric treatment based on symptoms alone will reduce in favour of targeted treatment for those parasitological-positive cases identified, even in hyper-endemic settings.

\section{Conclusion}

While these results should be interpreted within the limitations of the data and context described above, the associations identified in this study warrant further investigation. The significant role of rurality may be influenced by several factors, including (but not limited to) the important work of CHWs in improving health-literacy regarding symptom identification and facilitating early access to care.

Further mixed methods-oriented research may compliment quantitative data (for example that of Demographic and Health Surveys) to identify further barriers and enablers impacting upon inequities. Robust findings from such studies have the potential to improve access to essential child health services, both in dedicated facilities and within the community.

Although the findings from this study may not necessarily be generalized outside of this context, Uganda, like many other low-income countries, continues to experience significant variations in coverage levels for important child health interventions. Rurality and socioeconomic position undoubtedly impact upon a child's access to timely appropriate care and help to explain inequitable social and spatial variations in health outcomes. Whilst not available for inclusion in this study, additional equity variables, such as caregiver education status and ethnic grouping, would add value. Whilst beyond the scope of this study, gender assessments have already explored the important roles of women as primary caregivers in traditional patriarchal societies.

Greater understanding of the role and importance of these health determinants will assist policy-makers to better target early intervention programmes, whether in relation to enhancing health literacy, improving access to care, or other measures which positively discriminate in order to promote equity of health outcomes. Addressing these coverage gaps by targeting those most in need should remain a key strategy in the global effort to end preventable child morbidity and mortality. Such action will be critical if 
countries like Uganda are to meet the targets of reducing preventable child mortality and intra-country inequality as part of their commitments to the SDGs.

\section{Abbreviations}

ACTs Artemesinin-based combination therapies

CHWs Community Health Workers

cRCT cluster Randomized Controlled Trial

DHS Demographic and Health Surveys

HDSS Health and Demographic Surveillance Site

iCCM Integrated Community Case Management

IMCl Integrated Management of Childhood IIIness

MIS Malaria Indicator Survey

OR Odds ratio

RDTs Rapid diagnostic tests

SDGs Sustainable Development Goals

\section{Declarations}

\section{Ethics approval and consent to participate}

Ethics approval for the initial data collection was obtained from both Makerere University's School of Public Health Higher Degrees Research and Ethics Committee (IRB00005876) and the Uganda National Council of Science and Technology (HS898). Additional approval was gained from the Regional Ethics Committee of Karolinska Institutet (Dnr2011/1679-31/4). Informed consent to participate in the study was sought from all caregivers of children.

\section{Consent for publication}

Not applicable.

\section{Availability of data and materials}


The datasets analysed during the current study are available from the corresponding author on reasonable request.

\section{Competing interests}

The authors declare that they have no competing interests.

\section{Funding}

Swedish Institute for Development Agency (Sida) and UNICEF/UNDP/World Bank/WHO Special Program for Research and Training in Tropical Diseases.

(Disclaimer: The findings and conclusions in this article are those of the authors and do not necessarily represent the views of Sida or UNICEF/UNDP/World Bank/WHO Special Programme for Research and Training in Tropical Diseases.)

\section{Authors' contributions}

JNK and TA conceived and were involved in the original study design. JNK oversaw the collection of and provided the data for the study. DH analysed the data and drafted the manuscript. All authors interpreted the data, read and approved the final manuscript.

\section{Acknowledgements}

Not applicable.

\section{References}

1. United Nations. The Sustainable Development Goals Report 2018. New York: United Nations; 2018.

2. UN Inter-Agency Group for Child Mortality Estimation. Levels and trends in child mortality 2018. New York: UNICEF, WHO, World Bank Group \& United Nations; 2018.

3. Wang H, Liddell CA, Coates MM, Mooney MD, Levitz CE, Schumacher AE, et al. Global, regional, and national levels of neonatal, infant, and under-5 mortality during 1990-2013: a systematic analysis for the Global Burden of Disease Study 2013. Lancet. 2014;384(9947):957-79.

4. Shoo R. Reducing child mortality: the challenges in Africa. UN Chronicle. 2007. Available from: http://unchronicle.un.org/article/reducing-child-mortality-challenges-africa/. 
5. O'Hare B, Makuta I, Chiwaula L, Bar-Zeev N. G300 Upstream Barriers to Child Mortality Reduction: The Case of Sub Saharan Africa. Arch Dis Child. 2014;99(Suppl 1):A123-A.

6. Liu O. Hogan et al. Global, regional, and national causes of under-5 mortality in 2000-2015: an updated systematic analysis with implications for the Sustainable Development Goals. [Supplementary material] Lancet. 2016;388(10063):3027-35.

7. WHO, UNICEF. Ending preventable deaths from pneumonia and diarrhoea by 2025: the integrated global action plan for pneumonia and diarrhoea (GAPPD). Geneva: World Health Organization; 2013.

8. Matovu F, Nanyiti A, Rutebemberwa E. Household health care-seeking costs: experiences from a randomized, controlled trial of community-based malaria and pneumonia treatment among underfives in eastern Uganda. Malar J. 2014;13:222.

9. United Nations. Transforming our world: the 2030 Agenda for Sustainable Development. Resolution adopted by the General Assembly on 25 September 2015. A/RES/70/1. New York: United Nations; 2015.

10. WHO \& UNICEF. WHO/UNICEF joint statement on Integrated Community Case. Management (iCCM): an equity-focused strategy to improve access to essential treatment services for children. Geneva: 2012.

11. Barros AJ, Victora CG. Measuring coverage in $\mathrm{MNCH}$ : determining and interpreting inequalities in coverage of maternal, newborn, and child health interventions. PLoS Med. 2013;10(5):e1001390.

12. Victora CG, Requejo JH, Barros AJ, Berman P, Bhutta Z, Boerma T, et al. Countdown to 2015: a decade of tracking progress for maternal, newborn, and child survival. Lancet. 2015.

13. WHO. State of inequality: reproductive, maternal, newborn and child health. Geneva: World Health Organization; 2015.

14. Hosseinpoor AR, Bergen N, Schlotheuber A. Promoting health equity: WHO health equality monitoring at global and national levels. Glob Health Action [Internet]. 2015; 8.

15. Iganga-Mayuge HDSS. Iganga-Mayuge Health and Demographic Surveillance Site: Location of Iganga-Mayuge DHSS 2015 [updated 2015; cited 5 May]. Available from: http://igangamayugehdss.mak.ac.ug/index.php/en/location.

16. Kallander K, Hildenwall H, Waiswa P, Galiwango E, Peterson S, Pariyo G. Delayed care seeking for fatal pneumonia in children aged under five years in Uganda: a case-series study. Bull World Health Organ. 2008;86(5):332-8.

17. Kalyango JN. Integrated community case management of malaria and pneumonia in eastern Uganda: care-seeking, adherence, and community health worker performance. Stockholm: Karolinska Institutet; 2013.

18. Kalyango JN, Alfven T, Peterson S, Mugenyi K, Karamagi C, Rutebemberwa E. Integrated community case management of malaria and pneumonia increases prompt and appropriate treatment for pneumonia symptoms in children under five years in Eastern Uganda. Malar J. 2013;12:340.

19. Kalyango JN, Lindstrand A, Rutebemberwa E, Ssali S, Kadobera D, Karamagi C, et al. Increased Use of Community Medicine Distributors and Rational Use of Drugs in Children Less than Five Years of 
Age in Uganda Caused by Integrated Community Case Management of Fever. The American Journal of Tropical Medicine Hygiene. 2012;87(5 Suppl):36-45.

20. Kalyango JN, Rutebemberwa E, Alfven T, Ssali S, Peterson S, Karamagi C. Performance of community health workers under integrated community case management of childhood illnesses in eastern Uganda. Malar J. 2012;11:282.

21. Kalyango JN, Rutebemberwa E, Karamagi C, Mworozi E, Ssali S, Alfven T, et al. High adherence to antimalarials and antibiotics under integrated community case management of illness in children less than five years in eastern Uganda. PloS one. 2013;8(3):e60481.

22. Rutstein SO, Johnson K. The DHS wealth index: ORC Macro, MEASURE DHS; 2004.

23. Uganda Ministry of Health. Uganda Clinical Guidelines: National Guidelines for the Management of Common Conditions. Kampala: Ministry of Health; 2016.

24. Rutebemberwa E, Kallander K, Tomson G, Peterson S, Pariyo G. Determinants of delay in care-seeking for febrile children in eastern Uganda. Trop Med Int Health. 2009;14(4):472-9.

25. Ajayi IO, Browne EN, Garshong B, Bateganya F, Yusuf B, Agyei-Baffour P, et al. Feasibility and acceptability of artemisinin-based combination therapy for the home management of malaria in four African sites. Malar J. 2008;7:6.

26. Uganda Bureau of Stastistics, ICF International Inc. Uganda Demographic and Health Survey 2016. Kampala, Uganda (UBOS) and Calverton, Maryland (ICF International Inc.): 2018.

27. Uganda Bureau of Statistics and ICF Macro. Uganda Malaria Indicator Survey 2014-15. Calverton, MA: 2015.

28. Humphreys J, Solarsh G. Populations at special health risk: rural populations. In: Heggenhougen K, editor. International Encyclopaedia of Public Health: Elsevier; 2008. p. 242 - 53.

29. CSDH. Closing the gap in a generation: health equity through action on the social determinants of health. Geneva: 2008.

30. UNDP. Uganda Country Gender Assessment. New York: United Nations Development Program; October 2015.

31. Ettarh R, Galiwango E, Rutebemberwa E, Pariyo G, Peterson S. Spatial analysis of determinants of choice of treatment provider for fever in under-five children in Iganga. Uganda Health Place. 2011;17(1):320-6.

32. Bastiaens GJH, Bousema T, Leslie T. Scale-up of Malaria Rapid Diagnostic Tests and ArtemisininBased Combination Therapy: Challenges and Perspectives in Sub-Saharan Africa. PLoS Med. 2014;11(1):e1001590.

33. Wirth ME, Balk D, Delamonica E, Storeygard A, Sacks E, Minujin A. Setting the stage for equitysensitive monitoring of the maternal and child health Millennium Development Goals. Bull World Health Organ. 2006;84(7):519-27.

34. Barros AJ, Ronsmans C, Axelson H, Loaiza E, Bertoldi AD, Franca GV, et al. Equity in maternal, newborn, and child health interventions in Countdown to 2015: a retrospective review of survey data 
from 54 countries. Lancet. 2012;379(9822):1225-33.

35. WHO. Guidelines for the treatment of malaria. 2nd ed. Geneva: World Health Organization; 2010.

36. WHO. Integrated Management of Childhood Illness: Chart Booklet. Geneva: World Health Organization; 2014.

\section{Figures}

Caregivers of 1,095 children under-5 completed survey questionnaire Child younger than six months $(n=1)$, excluded

Completed questionnaire data relating to 1,094 children aged $6-59$ months

Child had symptoms during past 2 weeks?

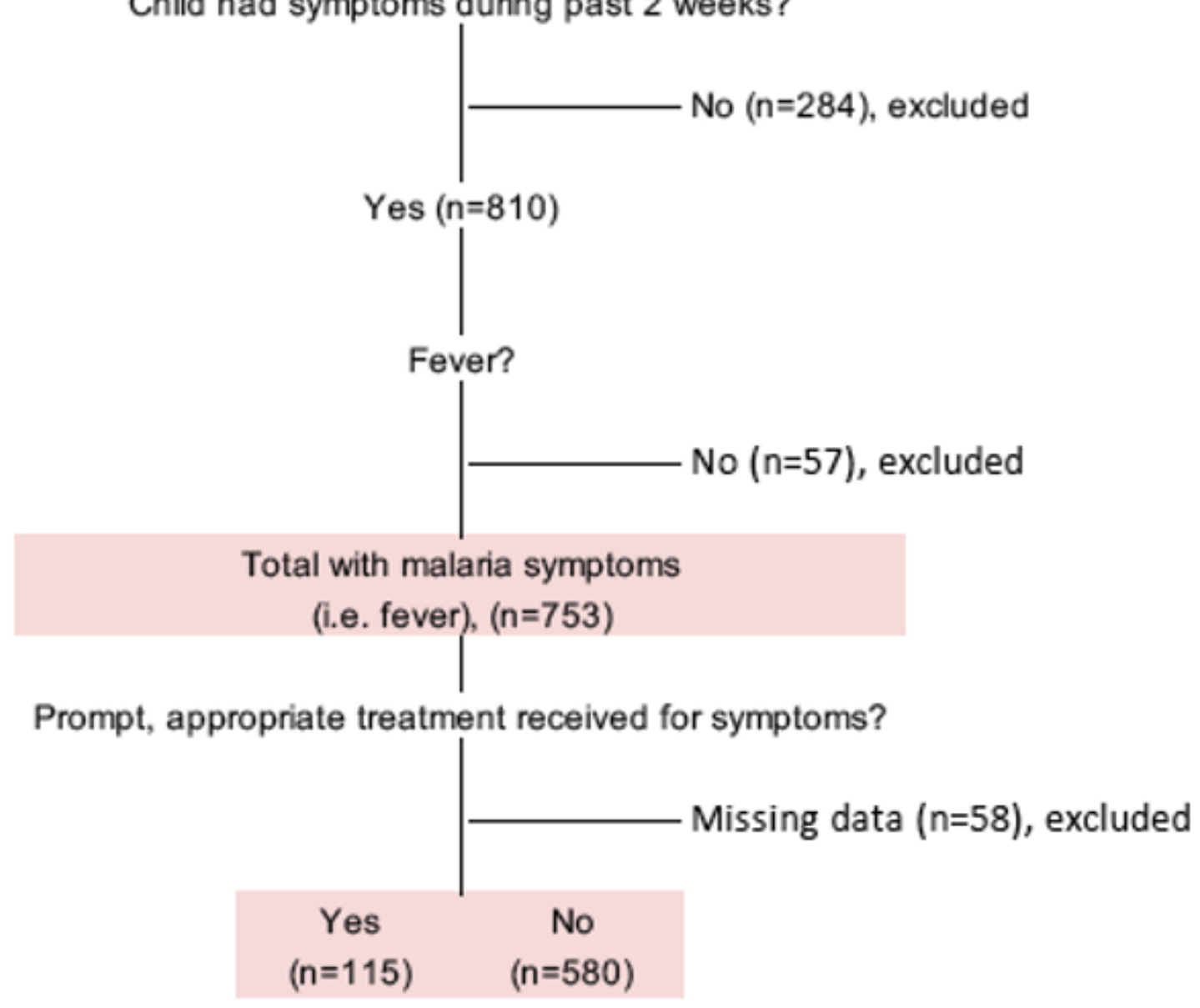

Figure 1

Algorithm of sampling framework 